\title{
Investigation on Calcined Magnesium-Based Mineral Powder and Its Behavior as Alternative Binder
}

\author{
G. Sugila Devi (iD) ${ }^{1}$ and K. Sudalaimani $\mathbb{D}^{2}$ \\ ${ }^{1}$ Department of Civil Engineering, Nadar Saraswathi College of Engineering and Technology, Theni 625531, Tamil Nadu, India \\ ${ }^{2}$ Department of Civil Engineering, Thiagarajar College of Engineering, Madurai 625015, Tamil Nadu, India
}

Correspondence should be addressed to K. Sudalaimani; ksudalaimani.civil@gmail.com

Received 22 April 2020; Revised 6 July 2020; Accepted 12 August 2020; Published 26 August 2020

Guest Editor: Nadezda Stevulova

Copyright ( $) 2020$ G. Sugila Devi and K. Sudalaimani. This is an open access article distributed under the Creative Commons Attribution License, which permits unrestricted use, distribution, and reproduction in any medium, provided the original work is properly cited.

\begin{abstract}
This paper investigates the behavior of calcined powder made of natural magnesite and natural steatite. The magnesite and steatite are made into a powder of ratio $3: 1$ by weight proportion, and the combination is thermally decomposed at a temperature of $1200^{\circ}$ Celsius. The calcined powder along with and without Sodium Tripolyphosphate (STPP) salt is tested for its microscopic structural development, consistency, initial setting time, final setting time, and heat of hydration. The powder is made into paste with water/ powder ratio as 0.25 and the hardened samples are tested for its compressive strength, drying shrinkage, $\mathrm{pH}$ value, $\mathrm{SEM}$ analysis, and XRD analysis. The results show that adding phosphate salt increases the hydration process, setting time, and strength aspects. The test samples are found with hydration products such as magnesium hydroxide and struvite. Thus, the present work shows that natural metamorphic magnesite and natural metamorphic steatite can be the potential alternative resource for the production of magnesium-based binder.
\end{abstract}

\section{Introduction}

There is an increasing concern over environmental impact of existing binders, such as ordinary portland cement. There are a lot of studies made to find the effective alternative binders. Alternative binders are a type of manmade mineral material which can react with water and/or $\mathrm{CO}_{2}$ and get hardened and can be later used to concrete or mortar as binder. The magnesium-based binders are considered to be the carbon negative as the water usage is reduced in comparison to Portland cement and the energy spent on preparing the magnesium-based cement will be lesser than calcium-based cement. This is due to lesser calcination temperature of magnesium-based cement with $650^{\circ} \mathrm{C}$ to $1200^{\circ} \mathrm{C}$ [1], when compared to calcium-based cement which has reacting temperature above $1300^{\circ} \mathrm{C}[2]$. The magnesium from reject desalination brine is studied and found that it can react with $\mathrm{CO}_{2}$ in atmosphere at $25^{\circ} \mathrm{C}$ to $65^{\circ} \mathrm{C}$ which is a breakthrough in carbon capture and utilization [3]. With this observation, it is understood that even with little higher emission of carbon dioxide during calcination, this reactive magnesium can capture the $\mathrm{CO}_{2}$ in atmosphere, ensuring ecofriendliness. The raw materials are varied in production of cement to reduce the stress on single raw material which can cause stress to the resource and resource depletion. Magnesium-based minerals are good alternative to calcium-based minerals which influence the strength development, microstructure, and $\mathrm{pH}$ of binders $[4,5]$. The magnesium oxychloride cement has higher strength due to the formation of magnesium hydroxide [6], and the mechanical behavior of magnesium oxysulfate cement is based on the relative contribution of porosity, pore size, and higher interparticle bonds [7]. The magnesium phosphate cement (MPC) has rapid setting, light weight properties, and also higher strength gain, and the MPC has a potential future of replacing the conventional cement [8]. The early studies show that the calcined magnesite has hydration reaction and this calcined magnesite can even replace $50 \%$ of ordinary portland cement [9]. The 
formation of the hydrate phase in the MgO-based cement is attributed to the hydromagnesite which also influences the formation of brucite [10]. Cement manufacturing is one of the major sources of greenhouse gas emissions. Global warming is one of the concerning problems, where finding a solution is imminent [11]. Steatite also known as soapstone is a schist which is rich in magnesium [12]. It is used in applications such as ceramics manufacturing [13] and preparation of panels for switchboards [14]. Limited works are only found on its application in cement industry.

Lot of research works were carried out previously to replace cement in concrete production by industry waste materials such as fly ash and rice husk ash. However, researchers were unable to find a way to completely replace cement in conventional concrete [15].

Magnesium has the property of reducing $\mathrm{pH}$ of mixture in which it is mixed [5]. It is also observed that addition of magnesium leads to early strength gain in concrete [16], and this could lead to utilizing steatite in concrete which will protect from adverse climatic conditions.

Steatite in its raw form is unable to deliver sufficient strength, so processing of raw material is obligatory. Furthermore, it is fine grinded for better results. A new kind of binder material, i.e., Magnesium Silicate Hydrate (MSH) gel is found when cement is partially replaced by steatite [17]. $\mathrm{MSH}$ gel is found to be much denser than CSH gel. However, synergy is not observed when steatite was used along with cement. One of the reasons could be its incompatibility in shapes, i.e., globules shape of MSH gel and sheet structure of $\mathrm{CSH}$ gel [4]. Researchers found that replacement up to $15 \%$ to the weight of cement in concrete was beneficial in strength gain [14].

In the previous works, researchers tried to use steatite as a raw feed for alkali-activated type binder [18]. As the process of alkali activation is a bit costly compared to conventional cement concrete, this research tries to find an economical as well as sustainable alternative.

Very limited works are carried out to assess the performance of calcined magnesite and steatite as binding material in the construction sector. This work proposes a novel binding substance, magnesium carbonate- and magnesium silicate-based calcined material with and without sodium tripolyphosphate (STPP) salt, which could replace the conventional mechanism in concrete. Furthermore, present work tries to achieve serviceable strength of binder by using magnesite- and steatite-based binder.

\section{Materials and Testing Procedures}

2.1. Materials Used in This Study. Naturally available metamorphic magnesium carbonate (magnesite) and naturally available metamorphic magnesium silicate are obtained and grinded to powder in ultrafine grinding ball mills. The properties of magnesite and steatite are given in Table 1 . The ratio of magnesite to steatite is maintained as $3: 1$ by weight of powder. The mixed powder of magnesite and steatite is placed in crucible and kept in muffle furnace for a temperature of $1200^{\circ}$ Celcius for a period of 3 hours. The temperature is fixed as the calcination process in magnesite starts above $850^{\circ} \mathrm{C}$, and at $1500^{\circ} \mathrm{C}$, it becomes dead burnt and agglomerated [19]; hence, the temperature is fixed at $1200^{\circ} \mathrm{C}$. Then, the powder is again grinded using ultradine ball mill. This sample is named as MB. A part of $\mathrm{MB}$ is then added with $5 \%$ of sodium tripolyphosphate and this sample is named as MPB. The properties of calcined magnesite and steatite $(\mathrm{MB})$ are given in Table 2. The samples used for strength and $\mathrm{pH}$ measurement have hardened for 28 days in ambient condition.

2.2. Sample Preparation and Testing Methodology. The consistency of powder and its Initial Setting Time (IST) and Final Setting Time (FST) are tested with Vicat's apparatus confirming to IS:4031-1988. The MB and MPB are made into paste with water. The water consistency is measured through Vicat's apparatus with a plunger where the trial pastes with water from $10 \%$ to $20 \%$ are prepared with different water percentages, and the sample which has Vicat's reading of $5 \mathrm{~mm}$ to $7 \mathrm{~mm}$ is taken as an appropriate sample through which the water requirement for the respective binder is identified. For preparation of hardened paste, the ratio of water to powder is taken as 0.25 and casted as cylinders with dimension of $10 \mathrm{~mm}$ diameter and $20 \mathrm{~mm}$ height. The samples are ambient cured in normal atmospheric temperature until testing days. The compressive strength is measured using Shimadzu compressive testing machine with the maximum capacity of $2000 \mathrm{kN}$. The shrinkage is measured using digital Vernier caliper on the standard samples, and the samples are unchanged and kept undisturbed for the testing period. The $\mathrm{pH}$ is measured by crushing the sample to powder and mixing it with 10 parts of neutral water for a period of 24 hours in flocculation set up, then the water is filtered, and $\mathrm{pH}$ is measured with $\mathrm{pH}$ meter. The heat of hydration is measured with digital thermal sensors with accuracy of $-50^{\circ}$ Celsius to $+50^{\circ}$ Celsius, and the sensor is immersed in the paste immediately after its preparation in the mold. The digital probe microscope scope is used to capture image of the paste in fresh state up to 500x magnification and the scanning electron microscope is used to capture and analyze the hardened samples up to $5000 \mathrm{x}$ magnification. The XRD analysis is carried out with a Siemens D-5000 X-ray diffractometer with $\mathrm{Cu} \mathrm{K}$-beta radiation and 2 scanning with a step size of $0.02^{\circ}$ and a measuring time of $10.00 \mathrm{Deg} / \mathrm{minute}$. A voltage of $40 \mathrm{kV}$ and current of $15 \mathrm{~mA}$ are used. Samples are collected from the cubes after 28 days of water curing and powdered in ball mills to pass through the sieve size of $90 \mu$.

\section{Results and Discussion}

The MB and MPB samples are tested for its various behavior and performances through standard procedures. 
TABLE 1: Magnesite and steatite properties.

\begin{tabular}{lcc}
\hline & Magnesite & Steatite \\
\hline Physical properties & & \\
Specific gravity & 3.2 & 2.7 \\
Loss of ignition (\%) & 45.99 & 3.33 \\
\hline Chemical properties & & \\
$\mathrm{SiO}_{2}(\%)$ & 8.97 & 62.67 \\
$\mathrm{Al}_{2} \mathrm{O}_{3}(\%)$ & 0.30 & 0.24 \\
$\mathrm{MgO}^{(\%)}$ & 43.54 & 33.26 \\
$\mathrm{Fe}_{2} \mathrm{O}_{3}(\%)$ & 0.64 & 0.30 \\
$\mathrm{CaO}(\%)$ & 0.56 & 0.20 \\
\hline
\end{tabular}

TABle 2: Properties of calcined powder (magnesite and steatite).

\begin{tabular}{lc}
\hline Properties & Values \\
\hline Blaine surface area $\left(\mathrm{m}^{2} / \mathrm{kg}\right)$ & 600 \\
Particle mean dia $(\mu \mathrm{m})$ & $<15$ \\
Specific gravity & 3.3 \\
\hline
\end{tabular}

To perform as a binder study on consistency, setting time and compressive strength are the important parameters. Table 3 shows the results of water consistency, setting time, and compressive strength of the samples. The results show that the requirement of water to initiate the paste phase of the MB powder is $15 \%$ and MPB powder is $16 \%$ by weight of powder. It is observed that the requirement of water is reduced by $40 \%$ to $50 \%$ compared to Ordinary Portland Cement. It is clear that the water usage can be reduced in this type of binding materials. The magnesium-based calcined powder with soluble phosphates increases the water resistance due to its lower concentration of $\mathrm{Mg}^{2+}$ ions possible [20]. The STPP has also brought early hydration and this tends to increase the water requirement by $1 \%$ than the $\mathrm{MB}$ sample. Even though the particle size is smaller in both powders, it does not affect the water consistency. Consequently, it reduces the burden of water usage compared to Ordinary Portland Cement. The results on setting time show that the MB sample sets faster than the MPB sample. The IST and FST of MB are $28 \%$ and $25 \%$, respectively, which are comparatively lesser than MPB samples. It can be understood that setting process of $\mathrm{MB}$ is faster when compared to MPB. The setting time is faster in the MB sample due to insufficient $\mathrm{H}+$ ions and this is altered in the MPB samples due to presence of soluble phosphates [21]. Table 3 and Figure 1 show the result on compressive strength of $\mathrm{MB}$ and MPB samples. The compressive strength results show that MPB performs well than the MB samples. The MPB has 50\%, 38\%, 39\%, and $42 \%$ higher strength gain on 3 days, 7 days, 14 days, and 28 days, respectively, in comparison with MB samples. The strength gain is attributed to the presence of phosphate in the MPB samples due to condensed microstructure in the MPB samples [22]. The drying shrinkage represented in Figure 2 shows that on initial days there are no shrinkage and as the days increase the shrinkage also increases for both MB and MPB samples. The MPB has $2.3 \%, 9.9 \%, 5.8 \%, 6.1 \%, 5.4 \%$, and $3.9 \%$ lesser shrinkage on 7 days, 14 days, 28 days, 42 days, 56 days, and 70 days, respectively, in comparison to MB samples. The shrinkage is lesser in comparison to the conventional OPC samples and behaves similar to that of earlier studies [23]. The strength development is due to the formation of magnesium hydroxide in MPB samples [24]. The $\mathrm{pH}$ value shown in Table 3 represents the hydrogen concentration, and this shows that the $\mathrm{MB}$ has a $\mathrm{pH}$ of 12.80 and MPB has 13.80, which is more alkaline than the standard OPC binder-based paste with a $\mathrm{pH}$ value between 11 and 13 .

The heat of hydration curve represented in Figure 3 shows that MPB starts with higher heat in comparison with $\mathrm{MB}$ and then slowly decreases and gets normalized within 1hour duration. There still has heat development even in 3 days, but it is observed that heat normalizes and the heat generation is constant even after 72 hours. This shows that there is sudden heat generation due to the setting of paste of MB and MPB samples due to the presence of reactive magnesia which also reflects in the setting time [25], and the heat produced is constant from day 0 to even after day 3 , which is notable.

Figure 4 shows the microscopic image of MB and MPB on 0 hours to 48 hours. From the microscopic image, it can be identified that $\mathrm{MB}$, from 0 hour to 1 hour, has much structural change, and after which no much change is observed. However, when compared to the 12 hours image both 24-hour and 48-hour images have a little broadened crack, apart from this no notable changes are observed. In MPB images, from 0-hour to 1-hour image, the structural difference is not as large as MB.

Figure 5 shows the scanning electron microscopic images, from which it can be seen that MPB samples have more amorphous products in comparison to MB sample, and the MPB sample is closely packed and there are very less microstructural pores. The MB sample shows the hydration product $\mathrm{Mg}(\mathrm{OH})_{2}$ in a needle-/floral-shaped structure. The calcination process induces reactive magnesium oxides. When the same reacts with water, the magnesium hydroxide products are formed. In addition, a small amount of $\mathrm{Mg}(\mathrm{OH})_{2}$ is inhibited through stabilization of $5 \mathrm{Mg}(\mathrm{OH})_{2} \mathrm{MgCl}_{2} 8 \mathrm{H}_{2} \mathrm{O}$ (HP) [26]. The MPB sample witnesses the presence of struvite in the irregular shape structure [27]. These struvite crystals are the important hydration products in magnesium phosphate cement [28] and the same is achieved here, which contributes to the strength of MPB samples [27, 28]. The HP is formed in very small intensity as observed in Figure 6, and this is due to the presence of chloride impurities in magnesite and steatite before calcination. Furthermore, the MPB sample has traces of struvite crystal (SC) [29]. Both HP and SC in MB and MPB samples act as hydration products which influence the hydration, setting time, and strength of the powder matrix.

Figure 6 shows the XRD analysis of MB and MPB. The MB samples show the presence of HP which is already confirmed through Figure 5. The presence of quartz is also identified due to the reaction of silicate in steatite. Next, the presence of $\mathrm{Mg}(\mathrm{OH})_{2}$ is evident in both $\mathrm{MB}$ and 
TABle 3: Test results on consistency, setting time, and strength development.

\begin{tabular}{lcccccccc}
\hline \multirow{2}{*}{ Sample ID } & \multirow{2}{*}{ Water consistency in percentage } & \multicolumn{2}{c}{$\begin{array}{c}\text { Setting time in } \\
\text { minutes }\end{array}$} & \multicolumn{3}{c}{ Compressive strength in MPa } \\
& & Initial & Final & 3 days & 7 days & 14 days & 28 days \\
\hline MB & 15.00 & 25.00 & 300.00 & 10.00 & 13.00 & 14.00 & 14.20 & 12.80 \\
MPB & 16.00 & 35.00 & 400.00 & 15.00 & 18.00 & 19.50 & 20.20 & 13.80 \\
\hline
\end{tabular}

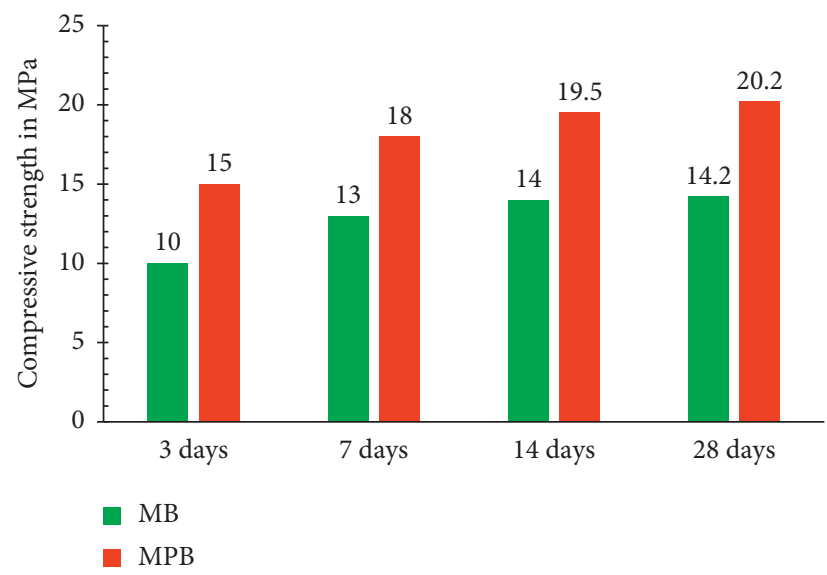

Figure 1: Compressive strength of MB and MPB samples.

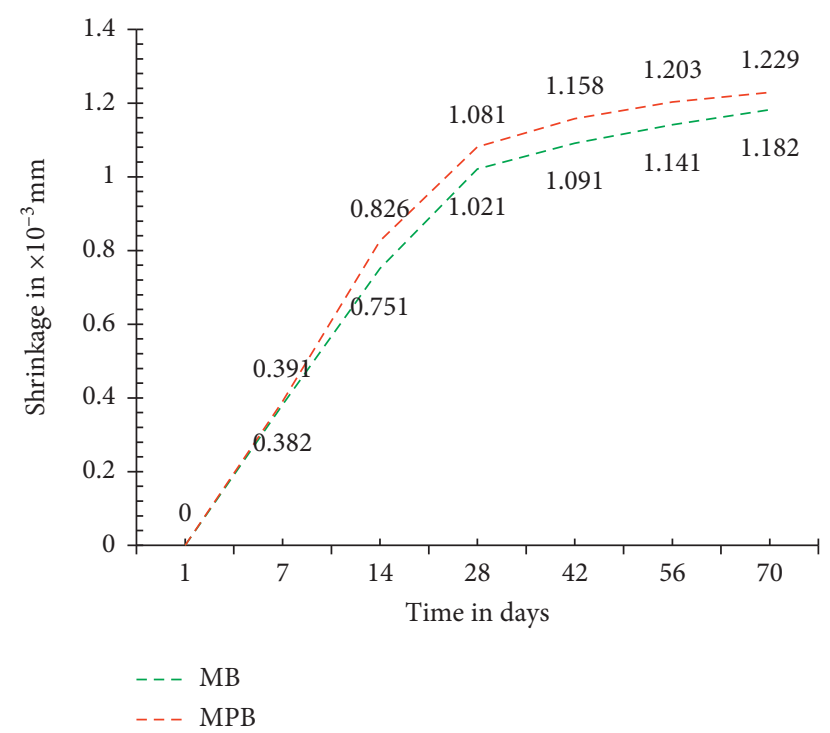

Figure 2: Drying shrinkage of MB and MPB samples.

MPB samples. The hydration is linked to $\mathrm{HP}$ in MB sample and struvite in the MPB sample. Both have considerable intensity of brucite, and it is observed that there is stable HP available which resists to form into $\mathrm{Mg}$ $(\mathrm{OH})_{2}$. Furthermore, it suggests the improved stability of HP against water requirement. The softening strength results in comparison to MPB samples are attributed to above discussed process [26]. The incorporation of STPP has brought increase in compressive strength and decrease in pore volumes as observed in the SEM images.
The MPB specimens show dense microstructure and struvite crystals fill the pores. These morphologies are due to the influence of STPP [30]. The struvite in presence of water is in more stable phase as studied in the earlier studies [31]. And also this availability of struvite has influence on compressive strength due to dissolutions [25]. Thus, the calcined magnesite and steatite have the properties which are similar to that of binders and few properties are similar to that of Ordinary Portland cement. 


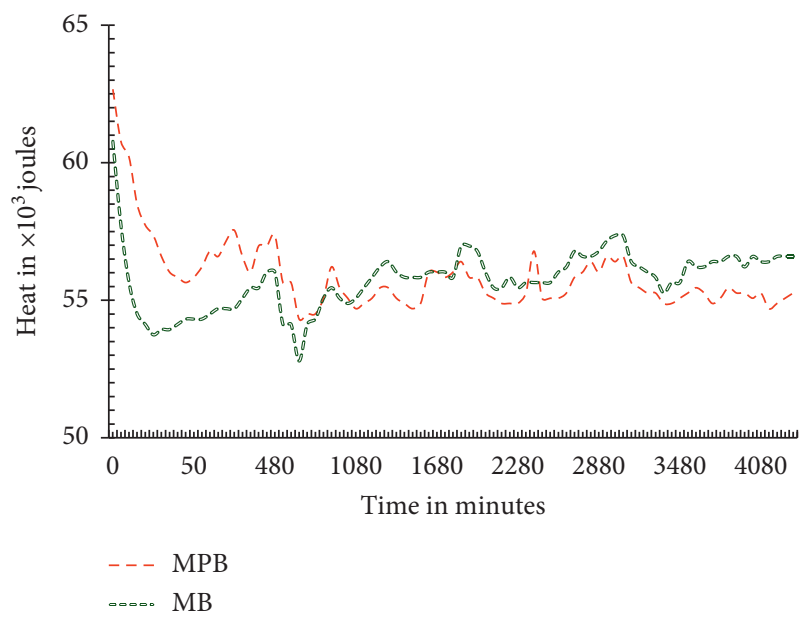

Figure 3: Heat measurement.

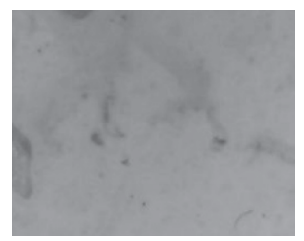

(a)

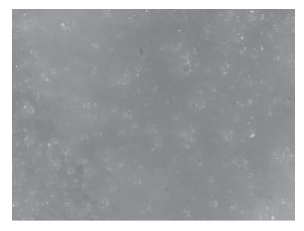

(f)

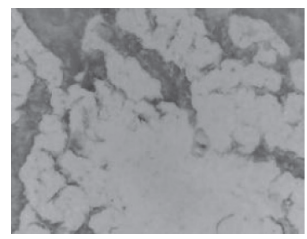

(b)

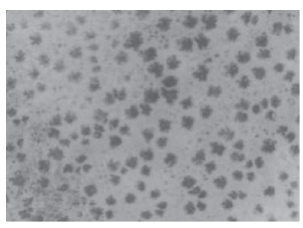

(g)

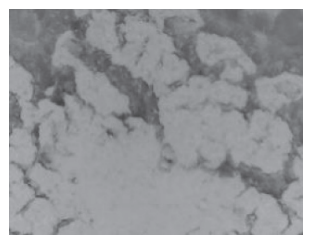

(c)

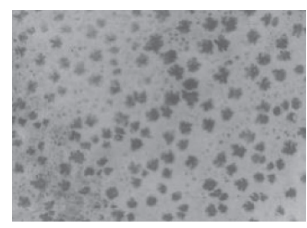

(h)

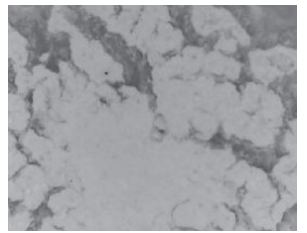

(d)

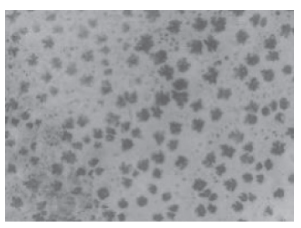

(i)

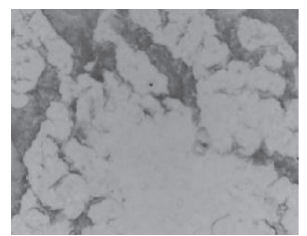

(e)

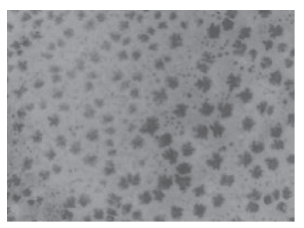

(j)

Figure 4: Microscopic images of MB and MPB. (a) MB: 0 hour. (b) MB: 1 hour. (c) MB: 12 hours. (d) MB:24 hours. (e) MB: 48 hours. (f) MPB: 0 hour. (g) MPB: 1 hour. (h) MPB: 12 hours. (i) MPB: 24 hours. (j) MPB: 48 hours.

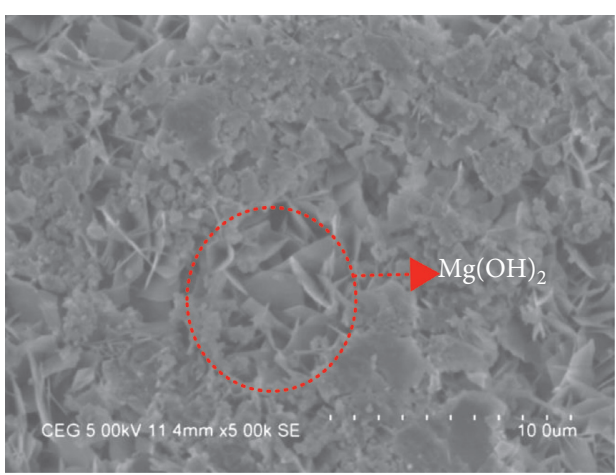

(a)

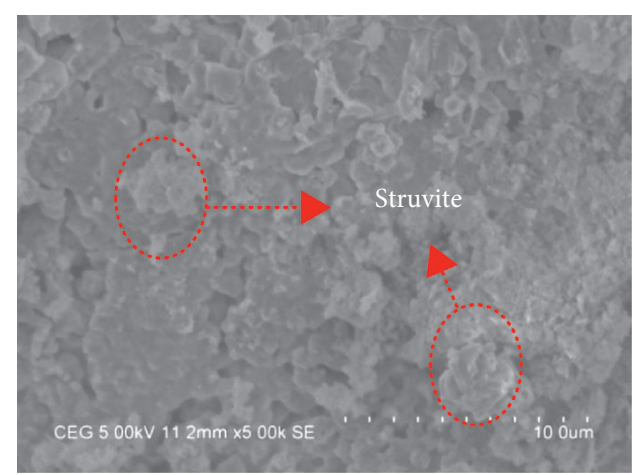

(b)

FIGURE 5: Scanning electron microscopic image of: (a) MB sample and (b) MPB sample. 


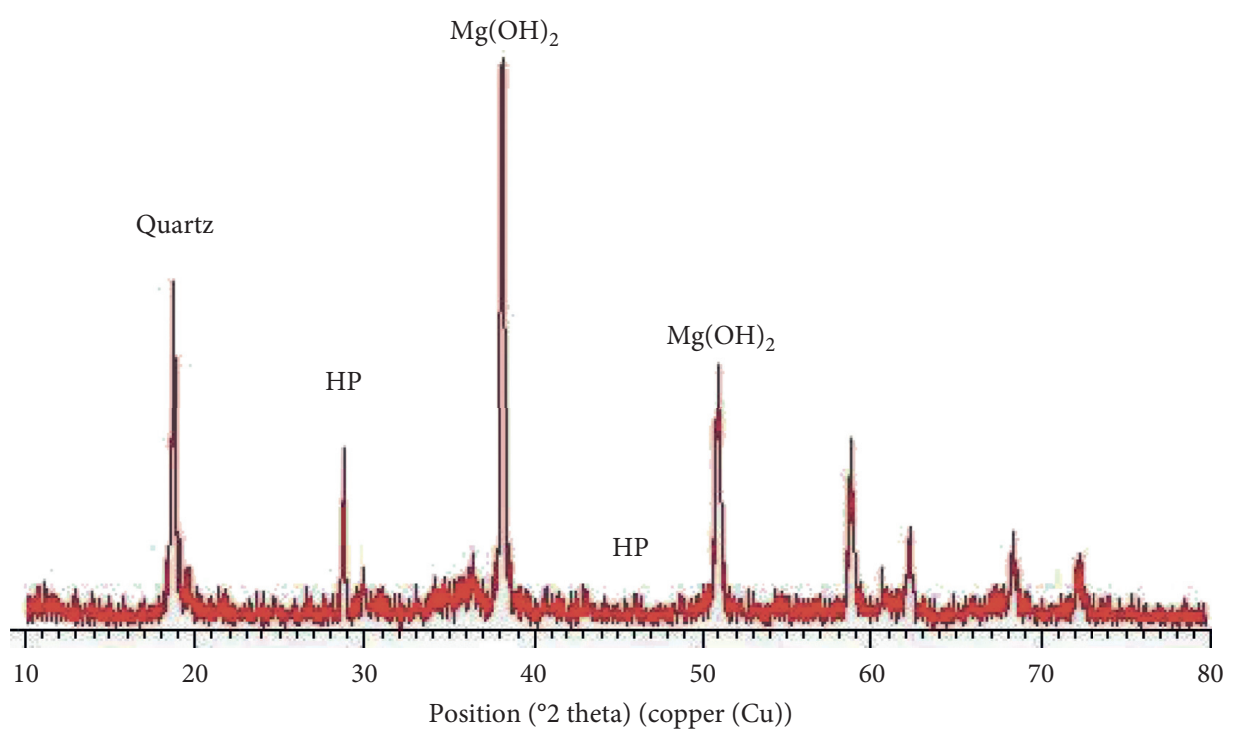

(a)

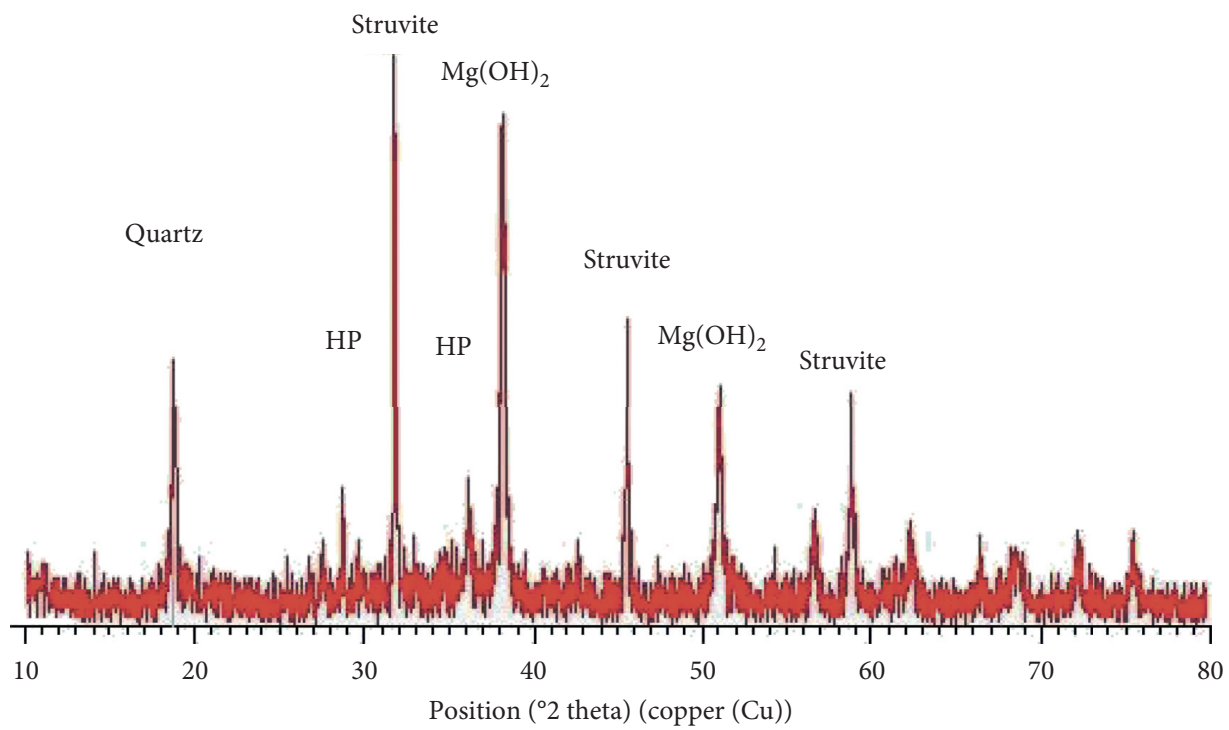

(b)

FIgURE 6: XRD analysis of (a) MB and (b) MPB sample.

\section{Conclusion}

The results of this study show that, unlike the mixture without phosphate, the mixture with the addition of phosphate represents the combination of 2 magnesiumbased cements, MSH and phosphate ones. The water requirement is decreased due to the lower concentration of magnesium ions in the calcined powder; consequently, it reduces the water requirement than Ordinary Portland cement. The setting and consistency are attributed to insufficient hydrogen ions in the MB sample which is rectified through addition of phosphates, and this process leads to better results in MPB samples. The addition of phosphate also increases the agglomeration of microstructure which attributes to the strength increment, and the strength is influenced through magnesium hydroxide which is evident in XRD analysis. The calcination process has induced reactive magnesia which influences the heat of hydration and strength attainment over a period. The presence of $\mathrm{Mg}(\mathrm{OH})_{2}$ and struvite influences the hydration and strength attainment. Thus, the study confirms that the calcined magnesite and steatite can be developed into a binder, and to improve the performance, the same phosphate has to be added which will give higher hydration and strength gain.

\section{Data Availability}

The data supporting this work are available in this article itself in Tables and Figures. Further clarification on the data will be available from the corresponding author upon request. 


\section{Conflicts of Interest}

The authors declare no conflicts of interest.

\section{References}

[1] A. Hasanbeigi, L. Price, and E. Lin, "Emerging energy-efficiency and $\mathrm{CO}_{2}$ emission-reduction technologies for cement and concrete production: a technical review," 2012.

[2] L. Mo, Y. Hao, Y. Liu, F. Wang, and M. Deng, "Preparation of calcium carbonate binders via $\mathrm{CO}_{2}$ activation of magnesium slag," Cement and Concrete Research, vol. 121, p. 81, 2019.

[3] J. Morrison, G. Jauffret, J. L. Galvez-Martos, and F. P. Glasser, "Magnesium-based cements for $\mathrm{CO}_{2}$ capture and utilisation," Cement and Concrete Research, vol. 85, p. 183, 2016.

[4] D. R. M. Brew and F. P. Glasser, "Synthesis and characterisation of magnesium silicate hydrate gels," Cement and Concrete Research, vol. 35, no. 1, p. 85, 2005.

[5] T. Zhang, C. R. Cheeseman, and L. J. Vandeperre, "Development of low $\mathrm{pH}$ cement systems forming magnesium silicate hydrate (M-S-H)," Cement and Concrete Research, vol. 41, no. 4, p. 439, 2011.

[6] J. J. Beaudoin and V. S. Ramachandran, "Strength development in magnesium oxychloride and other cements," Cement and Concrete Research, vol. 5, no. 6, p. 617, 1975.

[7] J. J. Beaudoin and V. S. Ramachandran, "Strength development in magnesium oxysulfate cement," Cement and Concrete Research, vol. 8, no. 1, p. 103, 1978.

[8] M. A. Haque and B. Chen, "Research progresses on magnesium phosphate cement: a review," 2019.

[9] J. Formosa, J. M. Chimenos, A. M. Lacasta, L. Haurie, and J. R. Rosell, "Novel fire-protecting mortars formulated with magnesium by-products," Cement and Concrete Research, vol. 41, no. 2, p. 191, 2011.

[10] F. Winnefeld, E. Epifania, F. Montagnaro, and E. M. Gartner, "Further studies of the hydration of MgO-hydromagnesite blends," Cement and Concrete Research, vol. 126, p. 105912, 2019.

[11] M. S. Shaikh, P. H. Shaikh, K. Qureshi, and I. Bhatti, "Green house effect and carbon foot print," 2018.

[12] A. Huhta and A. Kärki, "A proposal for the definition, nomenclature, and classification of soapstones," GFF, vol. 140, no. 1, pp. 38-43, 2018.

[13] H. Gökçe, D. Ağaoğulları, M. L. Öveçoğlu, İ. Duman, and T. Boyraz, "Characterization of microstructural and thermal properties of steatite/cordierite ceramics prepared by using natural raw materials," Journal of the European Ceramic Society, vol. 31, no. 14, pp. 2741-2747, 2011.

[14] R. Abinaya, K. G. Arunya, M. Gowsalya, and M. Malathy, "A new cement free binding material based on steatite powder activated through alkaline solution," Master Build, vol. 22, pp. 60-64, 2016.

[15] P. C. Hewlett, H. Justnes, and R. M. Edmeades, Cement and Concrete Admixtures, Elsevier, Berlin, Germany, 2019.

[16] K. Sudalaimani and M. Shanmugasundaram, "Influence of ultrafine natural steatite powder on setting time and strength development of cement," Advances in Materials Science and Engineering, vol. 2014, p. 1, 2014.

[17] P. Kumar, K. Sudalaimani, and M. Shanmugasundaram, "An investigation on self-compacting concrete using ultrafine natural steatite powder as replacement to cement," Advances in Materials Science and Engineering, vol. 2017, pp. 1-8, 2017.
[18] T. Luukkonen, Z. Abdollahnejad, J. Yliniemi, M. Mastali, P. Kinnunen, and M. Illikainen, "Alkali-activated soapstone waste - mechanical properties, durability, and economic prospects," Sustainable Materials and Technologies, vol. 22, 8 pages, 2019.

[19] C. Sadik, O. Moudden, A. El Bouari, and I. E. El Amrani, "Review on the elaboration and characterization of ceramics refractories based on magnesite and dolomite," 2016.

[20] D. Deng, "The mechanism for soluble phosphates to improve the water resistance of magnesium oxychloride cement," Cement and Concrete Research, vol. 235, 2003.

[21] X. Xu, X. Lin, X. Pan, T. Ji, Y. Liang, and H. Zhang, "Influence of silica fume on the setting time and mechanical properties of a new magnesium phosphate cement," Construction and Building Materials, vol. 235, 2020.

[22] B. Xu, B. Lothenbach, and F. Winnefeld, "Influence of wollastonite on hydration and properties of magnesium potassium phosphate cements," Cement and Concrete Research, vol. 131, 2020.

[23] J. Li, W. Zhang, and Y. Cao, "Laboratory evaluation of magnesium phosphate cement paste and mortar for rapid repair of cement concrete pavement," Construction and Building Materials, vol. 58, p. 122, 2014.

[24] Y. Liu and B. Chen, "Research on the preparation and properties of a novel grouting material based on magnesium phosphate cement," Construction and Building Materials, vol. 214, p. 516, 2019.

[25] B. Xu, B. Lothenbach, and H. Ma, "Properties of fly ash blended magnesium potassium phosphate mortars: effect of the ratio between fly ash and magnesia," Cement and Concrete Composites, vol. 90, p. 169, 2018.

[26] X. Luo, W. Fan, C. Li et al., "Effect of hydroxyacetic acid on the water resistance of magnesium oxychloride cement," Construction and Building Materials, vol. 246, 2020.

[27] Y. Liu, B. Chen, Z. Qin, D. Pen, and M. Aminul Haque, "Experimental research on properties and microstructures of magnesium-iron phosphate cement," Construction and Building Materials, vol. 257, 2020.

[28] Y. Liu, Z. Qin, and B. Chen, "Influence of low-grade bauxite on the properties of magnesium phosphate cement," Construction and Building Materials, vol. 242, 2020.

[29] Z. Qin, C. Ma, Z. Zheng, G. Long, and B. Chen, "Effects of metakaolin on properties and microstructure of magnesium phosphate cement," Construction and Building Materials, vol. 234, 2020.

[30] C. K. Chau, F. Qiao, and Z. Li, "Microstructure of magnesium potassium phosphate cement," Construction and Building Materials, vol. 25, no. 6, 2011.

[31] Z. Ding, Z. J. Li, and F. Xing, "Chemical durability investigation of magnesium phosphosilicate cement," 2006. 